\title{
Frailty as a Predictor of Disabilities among Community-Dwelling Older People: A Systematic Review and Meta-analysis
}

\author{
Gotaro Kojima, $\mathrm{MD}^{1}$ \\ ${ }^{1}$ Japan Green Medical Centre, London, United Kingdom.
}

Keywords: frailty, disability, activities of daily living, instrumental activities of daily living, community-dwelling older people.

\begin{abstract}
Background: Frailty has been shown to be associated with disability in the previous studies. However, it is not clear how consistently or to how much degree frailty is actually associated with the future disability risks.
\end{abstract}

Methods: A systematic review of the literature was conducted using Embase, MEDLINE, CINAHL, PsycINFO and the Cochrane Library for any prospective studies published from 2010 to September 2015 examining associations between baseline frailty status and subsequent risk of developing or worsening disabilities among community-dwelling older people. A meta-analysis was performed to synthesize pooled estimates.

Results: Of 7,012 studies identified through the systematic review, 20 studies were included in the meta-analysis. 12 studies examined ADL disability risks, two studies examined IADL disability risks, and six studies examined both ADL and IADL disability risks. Overall, frail older people were more likely to develop or worsen disabilities in ADL (12 studies, pooled $\mathrm{OR}=2.76,95 \% \mathrm{CI}=2.23-3.44, \mathrm{p}<0.00001 ; 5$ studies, pooled $\mathrm{HR}=2.23,95 \% \mathrm{CI}=1.42-3.49$, $\mathrm{p}<0.00001)$ and IADL (6 studies, pooled $\mathrm{OR}=3.62,95 \% \mathrm{CI}=2.32-5.64, \mathrm{p}<0.00001 ; 2$ studies, pooled $\mathrm{HR}=4.24,95 \% \mathrm{CI}=0.85-21.28, \mathrm{p}=0.08)$. Prefrailty was also associated with incident or worsening disability risks to a lesser degree in most pooled analyses. High heterogeneity observed among 12 studies with OR of ADL disability risks for frailty was explored using subgroup analyses, which suggested methodological quality and mean age of the cohort were the possible causes.

Conclusion: This systematic review meta-analysis quantitatively showed that frail older people are at higher risks of disabilities. These results are important for all related parties given population aging worldwide. Interventions for frailty are important to prevent disability and preserve physical functions, autonomy, and quality of life. 


\section{INTRODUCTION}

Frailty and disability were once used interchangeably due to the similarity, the high coexistence rate, and the lack of standardized definitions to operationalize frailty against disability. ${ }^{1-3}$ Frailty has now been conceptualized as a distinct state of decreased physiological reserve and compromised capacity to maintain homeostasis when exposed to a stressor resulting from age-related multiple accumulated deficits, thereby predisposing frail individuals to high vulnerability to adverse health outcomes. ${ }^{1-3}$ The adverse health outcomes include falls, fractures, hospitalization, institutionalization, dementia, and mortality. ${ }^{3-8}$ Prevalence of frailty is $10.7 \%$ among community-dwelling older people aged 65 and older and generally increases as people age ${ }^{9}$ and more than $90 \%$ of institutionalized people are frail. ${ }^{10}$ Frailty is a dynamic state and can transition to worse as well as better status over time. ${ }^{11}$ Given that frailty can be potentially prevented or reversed with interventions, such as exercise or nutritional supplementation, ${ }^{3}$ it was recommended by a consensus group of experts from international societies to screen older people aged 70 years or older with significant weight loss due to chronic disease. ${ }^{12}$

Although a number of definitions and criteria for frailty have been proposed, international consensus has yet to be reached partially because of the multidimensional and heterogeneous nature of the concept. ${ }^{3}$ Among a number of frailty definitions proposed, the ones described by Fried et al. in the Cardiovascular Health Study (CHS) have been most frequently used in the literature. ${ }^{2}$ They defined frailty as a clinical syndrome using a combination of five physical components: weight loss, exhaustion, weakness, slow walking speed, and low physical activity. ${ }^{2}$ In their original study, weakness was defined as having grip strength of less than 29$32 \mathrm{Kg}$ for men and $17-21 \mathrm{Kg}$ for women depending on BMI quartiles, slow walking speed was defined as taking more than 6-7 seconds to walk 15 feet stratified by gender and height, and low physical activity was defined as having less than $383 \mathrm{Kcals} /$ week for men and 270 Kcals/week for women for physical activity based on the short version of the Minnesota Leisure Time Activity questionnaire. ${ }^{2}$ The Frailty Index is another popular conceptualization of frailty. ${ }^{13}$ While CHS criteria involve mainly physical components, this method defines frailty according to accumulation of much broader health deficits including cognitive, psychological, and social factors in addition to physical aspects. ${ }^{14}$

Multiple studies have examined associations between frailty and disability and mostly found frail individuals were significantly more likely to develop or worsen disabilities than the nonfrail, ${ }^{2,3}$ but a few did not. ${ }^{15-17}$ Some researchers even state that frailty may be a physiologic precursor and etiologic factor in disability. ${ }^{2}$ It may feel obvious and not surprising that frailty is closely related to disability and predicts disability. However, since no systematic review or meta-analysis on the association was identified in the literature, it is not clear how consistently or to how much degree frailty is actually associated with the future disability risks.

One review paper has examined activities of daily living (ADL) disability risks predicted by not frailty but frailty components, such as weight loss or gait speed, and showed these frailty components individually predicted ADL disability. ${ }^{18}$ As described earlier, frailty is a multidimensional complex state, and its features of predicting disability risks cannot be completely evaluated by examining only an individual component of frailty. Furthermore, this review did not include instrumental activities of daily living (IADL) and did not conduct a meta-analysis to synthesize pooled risk estimates. ${ }^{18}$ Therefore, it was considered that quantifying the disability risks according to frailty by pooling the findings of the previous studies is new and confirms what was already known. The objectives of the current study 
were to perform a systematic review of the literature and to conduct a meta-analysis to synthesize pooled estimates of future disability risks predicted by baseline frailty status among community-dwelling older people.

\section{METHOD}

\section{Data Sources and Search Strategy}

A systematic review of the literature was conducted by one researcher based on a protocol developed in accordance with Preferred Reporting Items for Systematic Review and MetaAnalyses (PRISMA) ${ }^{19}$ and Meta-analysis of Observational Studies in Epidemiology $(\mathrm{MOOSE})^{20}$ statements using five electronic databases (Embase, MEDLINE, CINAHL Plus, PsycINFO, and the Cochrane Library) in September 2015. Any prospective studies in any language published in 2000 or later on associations between baseline frailty status and a subsequent risk of developing or worsening disabilities among community-dwelling older people were potentially eligible. Explosion functions were used if available. The Medical Subject Heading (MeSH) and keywords used were as follows: ((Activities of daily living (MeSH)) OR (Daily life activity (MeSH)) OR (Disability (MeSH)) OR (Disabilities (MeSH)) OR (ADL disability (MeSH)) OR (Physical disability (MeSH)) OR (Disabled (MeSH)) OR (Disabled person(s) (MeSH)) OR (Disabled personnel (MeSH)) OR (disable*) OR (disabilit*) OR ("activities of daily living") OR (ADL) OR (IADL)) AND ((Frailty syndrome $(\mathrm{MeSH}))$ OR (Frail elderly (MeSH)) OR (frailty)). The systematic search was repeated for update in June 2016 using the same strategy for the newer citations published from 2015 to June 2016. The reference lists of the retrieved articles were manually reviewed for any additional studies.

\section{Study Selection}

Studies were included if they met following inclusion criteria;

- Involved community-dwelling older people with mean age of 60 and older.

- Prospectively examined a risk of developing new disability or of worsening disability according to baseline frailty status defined by validated criteria originally designed to define frailty or its modified versions.

- Defined disability measured by activities of daily living (ADL) or instrumental activities of daily living (IADL).

- Provided odds ratio (OR) or hazard ratio (HR) as a risk measure for incidence or worsening of disability.

Studies were excluded with the following exclusion criteria;

- Defined frailty by slow walking speed or being certified for long-term care insurance, or used individual components of frailty criteria.

- Defined frailty status as a continuous measure, rather than categorizing as frail or nonfrail.

- Review papers, randomized controlled trials, conference abstracts, comments, or editorials.

When the same cohort was used for the same disability outcome, the study defining three categories: frail, prefrail, and robust, instead of two: frail and robust, or the study using the largest number of the individuals was included. When different frailty definitions were used in one study, the results based on CHS criteria, which is the most frequently used in the literature, ${ }^{3}$ or the results from the largest sample size were included. When different followup periods were used, the results of the longest follow-up period were used. These criteria were defined a priori. 
Studies potentially eligible for meta-analysis selected through systematic review of title, abstract, and full-text were examined for methodological quality using the Newcastle-Ottawa scale for cohort studies. ${ }^{21}$ A study was considered to have adequate quality to be included in the meta-analysis if they met half or more of the criteria.

\section{Data Extraction}

Data extracted were first author, cohort name if any, publication year, location (country), sample size of a cohort used for an analysis of interest or the entire cohort, proportion of female participants, age (mean or age criterion for inclusion), frailty criteria, disability outcome, effect measure, and follow-up period. OR and HR with corresponding 95\% confidence intervals $(95 \% \mathrm{CI})$ of disability risk for frailty and prefrailty compared with nonfrailty were extracted from each study. Adjusted risk measures were preferred to unadjusted ones.

\section{Statistical Analysis}

When two or more studies presented the same disability risk (incident ADL, worsening ADL, combined ADL, incident IADL, worsening IADL, or combined IADL) using the same type of risk estimates (OR or HR), the risk measures were combined to synthesize pooled estimates using the generic inverse variance method. Random-effects models were used since significant heterogeneity was expected given different methodology and various frailty and disability definitions used across the included studies.

Studies were pooled according to types of disability (ADL vs. IADL), type of risk (incident vs. worsening), effect measure (OR vs. HR), and frailty status (frail vs. prefrail) separately. Effects measures of incident and worsening disability were also pooled for the same type of disability and effect measure, for which estimates of worsening disability were selected over incidence disability when a study provided both estimates. Heterogeneity across the studies was assessed using Cochran's Q statistic and the degree of the heterogeneity was assessed using the $\mathrm{I}^{2}$ statistic. $\mathrm{I}^{2}$ values of $25 \%, 50 \%$, and $75 \%$ were considered as low, moderate, and high heterogeneity, respectively. ${ }^{22}$ When high heterogeneity was detected, subgroup analysis, sensitivity analysis, and random effects meta-regression were conducted according to location, sample size, female proportion of the cohort, mean age, frailty criteria, adjustment for an effect measure, follow-up period, and methodological quality to explore the potential source of heterogeneity. Publication bias was assessed using Begg-Mazumdar's and Egger's tests and visually examining funnel plots.

All analysis were performed using Review Manager 5 (version 5.2, The Cochrane Collaboration, Copenhagen, Denmark), IBM SPSS Statistics (version 22, IBM Corporation, New York, USA), and StatsDirect (version 2.8, StatsDirect, Cheshire, UK).

\section{RESULTS}

\section{Selection Processes}

The initial literature search using the five databases yielded 7,012 studies and 3 additional studies were identified from reference lists of relevant articles. Of a total of 7,015 studies, 2,892 duplicate studies were excluded and 4,085 studies were excluded because the titles or abstracts were considered as not relevant, leaving 38 studies for full-text review. Of these, 18 studies were excluded because nine studies did not provide OR or HR of disability risk for frailty status, three studies did not used ADL or IADL to measure disability, two studies had cohorts with mean age of less than 60 years, two studies used the same cohorts, and two 
studies were review or cross-sectional studies. Twenty studies were left and further assessed for methodological quality using the Newcastle-Ottawa scale for cohort studies. No additional studies were identified by the updated systematic review from 2015 to June 2016 . All the 20 studies were considered to have adequate quality (Table 1) and were included in this review and meta-analysis. Figure 1 shows a flowchart of the study selection with numbers of studies at each stage.

\section{Study Characteristics}

Study characteristics of the included 20 studies are summarized in Table 1. More than half of the included studies were published within the last four years (2012-2015). ${ }^{16,17,23-31}$ Nine studies were from the USA, ${ }^{2,29,32-38}$ five from Europe, ${ }^{15-17,23,30}$ two from Mexico, ${ }^{24,25}$ one each from Australia ${ }^{27}$ and Korea, ${ }^{26}$ and two studies used cohorts from multiple countries. ${ }^{28,31}$ Sample size varies from $226{ }^{16}$ to $40,332 .{ }^{31}$ Six studies used female-only cohorts ${ }^{27,31,33,34,36,38}$ and one study used an all-male cohort. ${ }^{35}$ Although not provided by all studies, mean age ranged from $68.7^{24}$ to $79.4^{23}$ years old. Most of the included studies $(80 \%, 16 / 20)$ used modified or original CHS criteria to define frailty. ${ }^{2,15,23,24,26,28-38}$ Prevalence of frailty varied substantially ranging from $4.3 \%{ }^{32}$ to $37.2 \% .^{24}$ Disability outcomes were either incident or worsening ADL or IADL disability. As many as $90 \%$ (18/20) of the studies examined ADL disability risks while IADL was examined by eight studies; two studies used IADL alone ${ }^{35,36}$ and six studies used both ADL and IADL. ${ }^{15,23,24,27,28,33}$ Twelve studies reported adjusted $\mathrm{OR}^{15,17,24,25,27-29,31,35-38}$ and two studies reported only unadjusted OR. ${ }^{16,26}$ All HR reported by six studies were adjusted for covariates. ${ }^{2,23,30,32-34}$ Follow-up periods were from 1 year ${ }^{16,31}$ to 11 years. $^{24}$

\section{Frailty as a Predictor of Incident or Worsening ADL Disability}

The meta-analysis of the associations between frailty and ADL disability included 12 studies with OR $^{15-17,24-29,31,37,38}$ and five studies with HR. ${ }^{2,23,30,32,34}$ Both frailty and prefrailty were significant predictors of ADL disability (incident, worsening, and combined) persistently in all meta-analysis. Eight ${ }^{15,17,24,25,28,31,37,38}$ and six $^{16,17,26-29}$ studies provided effect sizes as OR of incident and worsening ADL disability, respectively, for frailty compared with non-frailty (8 studies: pooled $\mathrm{OR}=2.8595 \% \mathrm{CI}=2.18-3.71, \mathrm{p}<0.00001,6$ studies: pooled $\mathrm{OR}=2.84$ $95 \% \mathrm{CI}=1.85-4.37, \mathrm{p}<0.00001$, respectively). There was no significant difference between these two groups $(\mathrm{p}=0.99)$. A pooled risk of combined incident and worsening ADL disability from 12 studies ${ }^{15-17,24-29,31,37,38}$ was also calculated (12 studies: pooled $\mathrm{OR}=2.76$, $95 \% \mathrm{CI}=2.22-3.44, \mathrm{p}<0.00001)$. High heterogeneity was observed among these three metaanalysis on incident, worsening, and combined ADL disability risks $\left(\mathrm{I}^{2}=84-94 \%\right)$. ADL disability risks for prefrailty were also calculated and showed to be significantly higher, but to a smaller degree than frailty, pooled disability risk estimates compared with non-frailty: 8 studies ${ }^{15,17,24,25,28,31,37,38}$ for incident ADL disability: pooled $\mathrm{OR}=1.64,95 \% \mathrm{CI}=1.44-1.87$, $\mathrm{p}<0.0001,4$ studies ${ }^{17,26,28,29}$ for worsening ADL disability: pooled $\mathrm{OR}=1.82,95 \% \mathrm{CI}=1.52$ 2.17 , p.00001 ( $\mathrm{p}=0.35$ for group difference), 10 studies $^{15,17,24-26,28,29,31,37,38}$ for combined ADL disability: pooled $\mathrm{OR}=1.70,95 \% \mathrm{CI}=1.52-1.91, \mathrm{p}<0.0001)$. Heterogeneity was low to moderate $\left(\mathrm{I}^{2}=30-43 \%\right)$ for these analyses for prefrailty. (Figure 2)

A total of five studies used HR to measure disability risks according to frailty. 2,23,30,32,34 Similarly to the studies with OR, among studies with HR, frailty was significantly associated with all incident, worsening, and combined ADL disability risks ( 2 studies: pooled HR=2.09, 95\% $\mathrm{CI}=1.56-2.80, \mathrm{p}<0.00001,3$ studies: pooled $\mathrm{HR}=2.38,95 \% \mathrm{CI}=1.13-4.99, \mathrm{p}<0.00001$, and 5 studies: pooled $\mathrm{HR}=2.23,95 \% \mathrm{CI}=1.42-3.49, \mathrm{p}<0.00001$, respectively). Prefrailty was also shown to be a significant predictor of incident, worsening, and combined ADL disability 
risks ( 2 studies: pooled $\mathrm{HR}=1.29,95 \% \mathrm{CI}=1.09-1.53, \mathrm{p}=0.004,2$ studies: pooled $\mathrm{HR}=2.05$, $95 \% \mathrm{CI}=1.08-3.90, \mathrm{p}=0.01$, and 4 studies: pooled $\mathrm{HR}=1.58,95 \% \mathrm{CI}=1.24-2.02, \mathrm{p}=0.01$, respectively). (Figure $2 \mathrm{~A}, \mathbf{B}$ )

\section{Frailty as a Predictor of Incident or Worsening IADL Disability}

IADL disability risks according to frailty were examined by six studies with $\mathrm{OR}^{15,24,27,28,35,36}$ and two studies with HR. ${ }^{23,33}$ Frailty compared with non-frailty was significantly associated with higher risk of incident, worsening, and combined IADL disability risks ( 3 studies ${ }^{15,24,28}$ : pooled $\mathrm{OR}=2.69,95 \% \mathrm{CI}=1.12-6.43, \mathrm{p}=0.0007,4$ studies $^{27,28,35,36}$ : pooled $\mathrm{OR}=4.57$, $95 \% \mathrm{CI}=2.79-7.47, \mathrm{p}<0.00001$, and 6 studies $^{15,24,27,28,35,36}$ : pooled $\mathrm{OR}=3.62,95 \% \mathrm{CI}=2.32$ $5.64, \mathrm{p}<0.00001$, respectively). While a pooled HR of incident IADL disability for prefrailty did not reach statistical significance $\left(3\right.$ studies $^{15,24,28}$ : pooled $\mathrm{HR}=1.35,95 \% \mathrm{CI}=0.86-2.10$, $\mathrm{p}=0.19)$, prefrailty was significantly associated with worsening and combined IADL disability risks $\left(3\right.$ studies $^{28,35,36}$ : pooled $\mathrm{HR}=1.92,95 \% \mathrm{CI}=1.19-3.09, \mathrm{p}=0.007$, and 5 studies $^{15,24,28,35,36}$ : pooled $\mathrm{HR}=1.55,95 \% \mathrm{CI}=1.08-2.21, \mathrm{p}<0.00001$, respectively). High degree of heterogeneity was observed among all the six meta-analyses $\left(\mathrm{I}^{2}=84-92 \%\right)$. (Figure 2 C, D)

\section{Subgroup Analysis, Sensitivity Analysis, Random Effects Meta-regression Analysis}

Subgroup, sensitivity, random effects meta-regression analyses were performed to explore possible causes of the high heterogeneity only in a group of 12 studies providing OR of combined ADL disability for frailty because other groups consisted of small numbers of studies $(\mathrm{n}<=6)$. The subgroup analysis were performed by grouping studies according to location (USA vs. non-USA), sample size $(n>=5000$ vs. $n<5000$ ), gender proportion (female only vs. rest), frailty criteria (CHS vs. non-CHS), follow-up period ( $>=4$ years vs. $<4$ years), methodological quality (Newcastle-Ottawa scale $>=6 / 8$ or $7 / 9$ vs. $<=5 / 8$ or $6 / 9$ ), and risk estimate adjustment (adjusted vs. unadjusted) (Table 2). Among these subgroups, two groups were found to have low heterogeneity: four studies ${ }^{15,17,25,37}$ with higher methodological quality (NOS $>=6 / 8$ or $7 / 9$ ) had $\mathrm{I}^{2}=0 \%$ and six studies ${ }^{15,17,24,25,29,37}$ with mean age $<75$ years had $\mathrm{I}^{2}=33 \%$. Between-subgroup differences were statistically non-significant in all pairs. In sensitivity analysis, removing any one or any two studies from 12 did not decrease $\mathrm{I}^{2}$ less than $75 \%$. Sample size, female proportion, mean age, follow-up period, and methodological quality scores were examined as a continuous variable for a potential modulator effect using random effect meta-regression models, which showed none of these factors were significantly associated with ADL disability risks according to frailty.

\section{Publication Bias Assessment}

Any study groups for the meta-analyses including four or more studies were examined for publication bias. No obvious asymmetry was observed in the funnel plots and Begg-

Mazumdar's and Egger's tests showed no evidence of publication bias in all of the six groups including the studies with 1) OR of incident ADL disability $(n=8), 2)$ OR of worsening ADL disability $(n=6), 3)$ OR of combined ADL disability $(n=12), 4)$ HR of combined ADL disability $(n=5), 5)$ OR of worsening IADL disability $(n=4)$, and 6) OR of combined IADL disability $(\mathrm{n}=5)$. (Figure $3 \mathbf{A}-\mathbf{F}$ )

\section{DISCUSSION}

This systematic review and meta-analysis provides the first pooled evidence that frailty is a significant predictor of ADL and IADL disability among community-dwelling older people. Those who were classified as frail had roughly two-fold or higher risks of incident, worsening, and combined ADL and IADL disability using OR and HR compared with those 
who were classified as non-frail. These disability risks were observed in prefrail individuals to a lesser degree.

Among the studies included in this review, 80\% (16/20) used CHS criteria to define frailty. All of these studies, except for the original paper, modified the original criteria slightly, presumably depending on the availability of data. ${ }^{39}$ These modifications might have had impacts on their results and possibly contributed to the high heterogeneity across the studies. However, the heterogeneity remains among both subgroups using CHS criteria ( $n=8, I^{2}=82 \%$, $\mathrm{p}<0.00001)$ and non-CHS criteria $\left(n=4, I^{2}=83 \%, p=0.0004\right)$ in the subgroup analysis. Some studies employed FI to define frailty status and examined risks of future disabilities. ${ }^{40,41}$ Although this continuous index can capture frailty status in a graded manner, it is not usually categorized into frail, prefrail, or robust as do the CHS criteria. For this reason, these studies could not be included in the meta-analysis to pool risk estimates. ${ }^{40,41}$ However, the findings of these studies are in line with the current meta-analysis and support frailty as a predictor of future disability risks. ${ }^{40,41}$

Most of the included studies provided risk estimates adjusted for potential confounders, at least age and gender (age only in male-only or female-only cohorts), except for two studies ${ }^{16,26}$ which provided only unadjusted estimates. As included in the criteria of the Newcastle-Ottawa scale, it is important to control for the potential confounding factors to examine independent associations between frailty and disability. Factors known to be associated with frailty include advanced age, female gender, low socioeconomic status, or low education. . $^{3,9}$

A wide range of functional measures were employed by the included studies to define disability (Table 3). In addition to six functions described by Katz; bathing, dressing, going to the toilet, transferring, continence, and feeding, ${ }^{42}$ and other functions used were walking, ${ }^{24,29,32}$ grooming, ${ }^{23,32}$ and cutting up food. ${ }^{28}$. A few studies just mentioned "activities of daily living"2,17 or "self-care and usual activities (work, school, family)" ${ }^{31}$ without specification. The studies examining IADL disability risks used all or some of eight IADL functions proposed by Lawton and Brody, namely using the telephone, shopping, food preparation, housekeeping, laundry, mode of transportation, responsibility for own medications, and ability to handle finances. ${ }^{43}$ One study ${ }^{23}$ used all of the eight functions and four $^{15,24,28,33}$ used some of the eight in addition to grooming ${ }^{15,24}$ or using a map ${ }^{28}$. Three studies simply stated "modified Lawton",27 or "5 IADLs"35,36. The different sets of ADL and IADL functions used as an outcome may possibly have yield different disability risks as well as the high degree of heterogeneity across the studies.

This review included two types of disability changes: incidence and worsening. Pooled estimates of worsening ADL and IADL disabilities were relatively higher than those of incidence (OR, ADL, prefrail vs. robust: 1.82 vs. 1.64, HR, ADL, frail vs. robust: 2.38 vs. 2.09, HR, ADL, prefrail vs. robust: 2.05 vs. 1.29 , OR, IADL, frail vs. robust: 4.57 vs. 2.69 , OR, IADL, prefrail vs. robust: 1.92 vs. 1.35), except for one pooled OR for ADL disability for frailty (2.84 vs. 2.85). Although none of these group differences were statistically significant, these findings may suggest that the elderly with disability are more likely to develop more disabilities compared with those without. Two studies provided both incidence and worsening of disability risks using the same cohorts. ${ }^{17,28}$ Macklai et al. examined risks of incident and worsening ADL and IADL disabilities according to frailty and prefrailty defined by modified CHS criteria ${ }^{28}$ using the Survey of Health, Ageing and Retirement in Europe 
(SHARE), a large cross-national panel database. They found four adjusted OR of incident and worsening ADL, and IADL disabilities were all comparable for frailty (aOR range: 5.11-5.59) and for prefrailty (aOR range: $1.65-2.27$ ).

This study has some limitations and the findings should be interpreted with caution. First, high heterogeneity was observed in most of the meta-analyses. This may be attributed to differences in methodologies and various definitions for frailty and disability used by the included studies. Although frailty criteria did not explain the heterogeneity, the studies with higher scores $\mathrm{n}$ methodological quality showed low heterogeneity in the subgroup analyses, which may suggest that the studies with a poorer methodology are potentially one of the causes of heterogeneity. The other characteristic suggested by the subgroup analysis was age. A substantial decrease in heterogeneity (from $\mathrm{I}^{2}=83 \%$ to $\mathrm{I}^{2}=33 \%$ ) was observed when including six studies with mean age $<75$ years, while high heterogeneity $\left(\mathrm{I}^{2}=90 \%\right)$ remained among three studies with mean age of 75 years or older. Advanced age may have contributed to the heterogeneity in the disability risks according to frailty across the included studies.Second, the systematic review and data extraction were conducted by one researcher and it would have been more decent if conducted by two independently.

The major strength of this study is the large number of included studies identified through systematic review of the literature in five electronic databases using an extensive and reproducible search strategy without language restriction. Furthermore, methodological quality, heterogeneity, and publication bias were examined. Subgroup and sensitivity analyses were also performed to explore the cause of high heterogeneity and found that poor methodological quality and higher mean age may have contributed to the heterogeneity.

\section{Conclusion}

This systematic review and meta-analysis has provided comprehensive and quantitative evidence that frailty is a significant predictor of future ADL and IADL disability risks among community-dwelling older people. These results may become of more importance for clinicians, researchers, and policymakers because there will be more older people as world populations age and developing interventions for frailty is increasingly a pressing priority to prevent disability and preserve older people's physical functions as well as their autonomy and quality of life. ${ }^{44}$

\section{DECLARATION OF INTERST}

The author reports no conflicts of interest.

\section{REFERENCES}

[1]. Walston J, Hadley EC, Ferrucci L, et al. Research agenda for frailty in older adults: toward a better understanding of physiology and etiology: summary from the American Geriatrics Society/National Institute on Aging Research Conference on Frailty in Older Adults. J Am Geriatr Soc 2006;54:991-1001.

[2]. Fried LP, Tangen CM, Walston J, et al. Frailty in older adults: evidence for a phenotype. J Gerontol A Biol Sci Med Sci 2001;56:M146-156.

[3]. Clegg A, Young J, Iliffe S, Rikkert MO, Rockwood K. Frailty in elderly people. Lancet 2013;381:752-762.

[4]. Kojima G, Taniguchi Y, Iliffe S, Walters K. Frailty as a Predictor of Alzheimer Disease, Vascular Dementia, and All Dementia Among Community-Dwelling Older People: A Systematic Review and Meta-Analysis. J Am Med Dir Assoc 2016;

[5]. Kojima G. Frailty as a predictor of hospitalisation among community-dwelling older 
people: a systematic review and meta-analysis. J Epidemiol Community Health 2016;70:722-729.

[6]. Kojima G. Frailty as a predictor of fractures among community-dwelling older people: A systematic review and meta-analysis. Bone 2016;90:116-122.

[7]. Kojima G. Frailty as a Predictor of Nursing Home Placement Among CommunityDwelling Older Adults: A Systematic Review and Meta-analysis. J Geriatr Phys Ther 2016;

[8]. Kojima G. Frailty as a Predictor of Future Falls Among Community-Dwelling Older People: A Systematic Review and Meta-Analysis. J Am Med Dir Assoc 2015;16:1027-1033.

[9]. Collard RM, Boter H, Schoevers RA, Oude Voshaar RC. Prevalence of frailty in community-dwelling older persons: a systematic review. J Am Geriatr Soc 2012;60:1487-1492.

[10]. Kojima G. Prevalence of Frailty in Nursing Homes: A Systematic Review and MetaAnalysis. J Am Med Dir Assoc 2015;16:940-945.

[11]. Gill TM, Gahbauer EA, Allore HG, Han L. Transitions between frailty states among community-living older persons. Arch Intern Med 2006;166:418-423.

[12]. Morley JE, Vellas B, van Kan GA, et al. Frailty consensus: a call to action. J Am Med Dir Assoc 2013;14:392-397.

[13]. Mitnitski AB, Mogilner AJ, Rockwood K. Accumulation of deficits as a proxy measure of aging. ScientificWorldJournal 2001;1:323-336.

[14]. Searle SD, Mitnitski A, Gahbauer EA, Gill TM, Rockwood K. A standard procedure for creating a frailty index. BMC Geriatr 2008;8:24.

[15]. Avila-Funes JA, Helmer C, Amieva H, et al. Frailty among community-dwelling elderly people in France: the three-city study. J Gerontol A Biol Sci Med Sci 2008;63:1089-1096.

[16]. Bilotta C, Nicolini P, Case A, Pina G, Rossi S, Vergani C. Frailty syndrome diagnosed according to the Study of Osteoporotic Fractures (SOF) criteria and adverse health outcomes among community-dwelling older outpatients in Italy. A one-year prospective cohort study. Arch Gerontol Geriatr 2012;54:e23-28.

[17]. Forti P, Maioli F, Lega MV, Montanari L, Coraini F, Zoli M. Combination of the clock drawing test with the physical phenotype of frailty for the prediction of mortality and other adverse outcomes in older community dwellers without dementia. Gerontology 2014;60:204-211.

[18]. Vermeulen J, Neyens JC, van Rossum E, Spreeuwenberg MD, de Witte LP. Predicting ADL disability in community-dwelling elderly people using physical frailty indicators: a systematic review. BMC Geriatr 2011;11:33.

[19]. Moher D, Liberati A, Tetzlaff J, Altman DG. Preferred reporting items for systematic reviews and meta-analyses: the PRISMA statement. BMJ 2009;339:b2535.

[20]. Stroup DF, Berlin JA, Morton SC, et al. Meta-analysis of observational studies in epidemiology: a proposal for reporting. Meta-analysis Of Observational Studies in Epidemiology (MOOSE) group. JAMA 2000;283:2008-2012.

[21]. Wells GA, Shea D, O'Connell D, et al. The Newcastle-Ottawa Scale (NOS) for assessing the quality of nonrandomised studies in meta-analyses. http://www.ohri.ca/programs/clinical_epidemiology/oxford.asp. Accessed 24 September, 2015.

[22]. Higgins JP, Thompson SG, Deeks JJ, Altman DG. Measuring inconsistency in metaanalyses. BMJ 2003;327:557-560.

[23]. Abizanda P, Romero L, Sanchez-Jurado PM, Martinez-Reig M, Gomez-Arnedo L, Alfonso SA. Frailty and mortality, disability and mobility loss in a Spanish cohort of 
older adults: the FRADEA study. Maturitas 2013;74:54-60.

[24]. Aguilar-Navarro SG, Amieva H, Gutierrez-Robledo LM, Avila-Funes JA. Frailty among Mexican community-dwelling elderly: a story told 11 years later. The Mexican Health and Aging Study. Salud Publica Mex 2015;57 Suppl 1:S62-69.

[25]. Diaz de Leon Gonzalez E, Tamez Perez HE, Gutierrez Hermosillo H, Cedillo Rodriguez JA, Torres G. [Frailty and its association with mortality, hospitalization and functional dependence in Mexicans aged 60-years or older]. Med Clin (Barc) 2012;138:468-474.

[26]. Jung HW, Kim SW, Ahn S, et al. Prevalence and outcomes of frailty in Korean elderly population: comparisons of a multidimensional frailty index with two phenotype models. PLoS One 2014;9:e87958.

[27]. Lopez D, Flicker L, Dobson A. Validation of the frail scale in a cohort of older Australian women. J Am Geriatr Soc 2012;60:171-173.

[28]. Macklai NS, Spagnoli J, Junod J, Santos-Eggimann B. Prospective association of the SHARE-operationalized frailty phenotype with adverse health outcomes: evidence from $60+$ community-dwelling Europeans living in 11 countries. BMC Geriatr 2013;13:3.

[29]. Paulson D, Lichtenberg PA. The Paulson-Lichtenberg Frailty Index: evidence for a self-report measure of frailty. Aging Ment Health 2015;19:892-901.

[30]. Solfrizzi V, Scafato E, Frisardi V, et al. Frailty syndrome and all-cause mortality in demented patients: the Italian Longitudinal Study on Aging. Age (Dordr) 2012;34:507-517.

[31]. Tom SE, Adachi JD, Anderson FA, Jr., et al. Frailty and fracture, disability, and falls: a multiple country study from the global longitudinal study of osteoporosis in women. $\mathrm{J}$ Am Geriatr Soc 2013;61:327-334.

[32]. Al Snih S, Graham JE, Ray LA, Samper-Ternent R, Markides KS, Ottenbacher KJ. Frailty and incidence of activities of daily living disability among older Mexican Americans. J Rehabil Med 2009;41:892-897.

[33]. Bandeen-Roche K, Xue QL, Ferrucci L, et al. Phenotype of frailty: characterization in the women's health and aging studies. J Gerontol A Biol Sci Med Sci 2006;61:262266.

[34]. Boyd CM, Xue QL, Simpson CF, Guralnik JM, Fried LP. Frailty, hospitalization, and progression of disability in a cohort of disabled older women. Am J Med 2005;118:1225-1231.

[35]. Ensrud KE, Ewing SK, Cawthon PM, et al. A comparison of frailty indexes for the prediction of falls, disability, fractures, and mortality in older men. J Am Geriatr Soc 2009;57:492-498.

[36]. Ensrud KE, Ewing SK, Taylor BC, et al. Comparison of 2 frailty indexes for prediction of falls, disability, fractures, and death in older women. Arch Intern Med 2008;168:382-389.

[37]. Sarkisian CA, Gruenewald TL, John Boscardin W, Seeman TE. Preliminary evidence for subdimensions of geriatric frailty: the MacArthur study of successful aging. J Am Geriatr Soc 2008;56:2292-2297.

[38]. Woods NF, LaCroix AZ, Gray SL, et al. Frailty: emergence and consequences in women aged 65 and older in the Women's Health Initiative Observational Study. J Am Geriatr Soc 2005;53:1321-1330.

[39]. Theou O, Cann L, Blodgett J, Wallace LM, Brothers TD, Rockwood K. Modifications to the frailty phenotype criteria: Systematic review of the current literature and investigation of 262 frailty phenotypes in the Survey of Health, Ageing, and Retirement in Europe. Ageing Res Rev 2015;21:78-94. 
[40]. Theou O, O'Connell MD, King-Kallimanis BL, O'Halloran AM, Rockwood K, Kenny RA. Measuring frailty using self-report and test-based health measures. Age Ageing 2015;44:471-477.

[41]. Woo J, Goggins W, Sham A, Ho SC. Public health significance of the frailty index. Disabil Rehabil 2006;28:515-521.

[42]. Katz S, Downs TD, Cash HR, Grotz RC. Progress in development of the index of ADL. Gerontologist 1970;10:20-30.

[43]. Lawton MP, Brody EM. Assessment of older people: self-maintaining and instrumental activities of daily living. Gerontologist 1969;9:179-186.

[44]. Kojima G, Iliffe S, Jivraj S, Walters K. Association between frailty and quality of life among community-dwelling older people: a systematic review and meta-analysis. J Epidemiol Community Health 2016;70:716-721. 
Table 1. Summary of included studies on frailty and disabilities among community-dwelling older people.

\begin{tabular}{|c|c|c|c|c|c|c|c|c|c|c|}
\hline Author/Study & Year & Location & $\begin{array}{l}\text { Sample } \\
\text { size* }\end{array}$ & $\begin{array}{l}\text { Female } \\
(\%)\end{array}$ & Age & $\begin{array}{l}\text { Frailty } \\
\text { criteria }\end{array}$ & $\begin{array}{l}\text { disability } \\
\text { outcome }\end{array}$ & $\begin{array}{l}\begin{array}{l}\text { Effect } \\
\text { measure }\end{array} \\
\text { nes }\end{array}$ & $\begin{array}{l}\text { Follow- } \\
\text { up period }\end{array}$ & NOS \\
\hline $\begin{array}{l}\text { Aguilar-Navarro et } \\
\text { al. }{ }^{19} \\
\text { Mexican Health and } \\
\text { Aging Study }\end{array}$ & 2015 & Mexico & $\begin{array}{l}2,509 \\
2,542\end{array}$ & $53.6 \%$ & 68.7 & $\mathrm{mCHS}$ & $\begin{array}{l}\text { Incident ADL } \\
\text { Incident IADL }\end{array}$ & $\mathrm{aOR}$ & 11 years & $6 / 9$ \\
\hline $\begin{array}{l}\text { Paulson et al. }{ }^{24} \\
\text { Health and Retirement } \\
\text { Study }\end{array}$ & 2015 & USA & 8,844 & $58.8 \%$ & 74.5 & $\mathrm{mCHS}$ & Worsening ADL & $\mathrm{aOR}$ & $\begin{array}{l}4 \text { years } \\
8 \text { years }\end{array}$ & $5 / 8$ \\
\hline $\begin{array}{l}\text { Forti et al. }{ }^{12} \\
\text { Conselice Study of } \\
\text { Brain Aging }\end{array}$ & 2014 & Italy & $\begin{array}{l}486 \\
601\end{array}$ & $53.4 \%$ & 73.6 & $\mathrm{mSOF}$ & $\begin{array}{l}\text { Incident ADL } \\
\text { Worsening ADL }\end{array}$ & $\mathrm{aOR}$ & 3 years & $8 / 9$ \\
\hline $\begin{array}{l}\text { Jung et al. }{ }^{21} \\
\text { Korean Longitudinal } \\
\text { Study on Health and } \\
\text { Aging }\end{array}$ & 2014 & Korea & 621 & $50.8 \%$ & 75.9 & $\mathrm{mCHS}$ & Worsening ADL & uOR & 5.6 years & $5 / 8$ \\
\hline $\begin{array}{l}\text { Abizanda et al. }{ }^{18} \\
\text { Frailty and } \\
\text { Dependence in } \\
\text { Albacete Study }\end{array}$ & 2013 & Spain & $\begin{array}{l}756 \\
742\end{array}$ & $60.5 \%$ & 79.4 & $\mathrm{mCHS}$ & $\begin{array}{l}\text { Worsening ADL } \\
\text { Worsening IADL }\end{array}$ & aHR & 1.5 years & $6 / 8$ \\
\hline $\begin{array}{l}\text { Macklai et al. }{ }^{23} \\
\text { Survey of Health, } \\
\text { Ageing and Retirement }\end{array}$ & 2013 & Multiple $\dagger$ & $\begin{array}{l}9,176 \\
10,187 \\
8,495 \\
10,177 \\
\end{array}$ & - & $\geq 60$ & $\mathrm{mCHS}$ & $\begin{array}{l}\text { Incident ADL } \\
\text { Worsening ADL } \\
\text { Incident IADL } \\
\text { Worsening IADL }\end{array}$ & $\mathrm{aOR}$ & 2 years & $6 / 9$ \\
\hline $\begin{array}{l}\text { Tom et al. }{ }^{26} \\
\text { Global Longitudinal } \\
\text { Study of Osteoporosis } \\
\text { in Women }\end{array}$ & 2013 & Multiple & 40,332 & $100 \%$ & $\geq 55$ & $\mathrm{mCHS}$ & Incident ADL & $\mathrm{aOR}$ & 1 year & $6 / 9$ \\
\hline Bilotta et al. ${ }^{11}$ & 2012 & Italy & 226 & $71.3 \%$ & 81.5 & $\mathrm{mSOF}$ & Worsening ADL & uOR & 1 year & $4 / 8$ \\
\hline $\begin{array}{l}\text { Diaz de Leon Gonzalez } \\
\text { et al. }{ }^{20}\end{array}$ & 2012 & Mexico & 2537 & $53.4 \%$ & 68.4 & $\mathrm{mSOF}$ & Incident ADL & $\mathrm{aOR}$ & 2 years & $8 / 9$ \\
\hline $\begin{array}{l}\text { Lopes et al. }{ }^{22} \\
\text { Australian } \\
\text { Longitudinal Study on } \\
\text { Women's Health } \\
\end{array}$ & 2012 & Australia & 8,646 & $100 \%$ & 77.8 & $\begin{array}{l}\text { FRAIL } \\
\text { scale }\end{array}$ & $\begin{array}{l}\text { Worsening ADL } \\
\text { Worsening IADL }\end{array}$ & $\mathrm{aOR}$ & 6.8 years & $5 / 8$ \\
\hline $\begin{array}{l}\text { Solfrizzi et al. }{ }^{25} \\
\text { Italian Longitudinal } \\
\text { Study of Aging }\end{array}$ & 2012 & Italy & $\begin{array}{l}2,193 \\
2,121\end{array}$ & $45.2 \%$ & 73.1 & $\mathrm{mCHS}$ & Worsening ADL & aHR & $\begin{array}{l}3 \text { years } \\
7 \text { years }\end{array}$ & $6 / 8$ \\
\hline $\begin{array}{l}\text { Al Snih et al. }{ }^{27} \\
\text { Hispanic Established } \\
\text { Populations for the } \\
\text { Epidemiologic Study } \\
\text { of the Elderly }\end{array}$ & 2009 & USA & 1,645 & $57.7 \%$ & 74.3 & $\mathrm{mCHS}$ & Incident ADL & aHR & 10 years & $7 / 9$ \\
\hline $\begin{array}{l}\text { Ensrud et al. }{ }^{30} \\
\text { Osteoporotic Fractures } \\
\text { in Men Study }\end{array}$ & 2009 & USA & 2,891 & $0 \%$ & 76.4 & $\mathrm{mCHS}$ & Worsening IADL & $\mathrm{aOR}$ & 1.2 years & $4 / 8$ \\
\hline $\begin{array}{l}\text { Avila-Funes et al. }{ }^{10} \\
\text { Three-City Study }\end{array}$ & 2008 & France & $\begin{array}{l}5,449 \\
5,029 \\
\end{array}$ & $61.3 \%$ & 74.1 & $\mathrm{mCHS}$ & $\begin{array}{l}\text { Incident ADL } \\
\text { Incident IADL }\end{array}$ & $\mathrm{aOR}$ & 4 years & $7 / 9$ \\
\hline $\begin{array}{l}\text { Ensrud et al. }{ }^{31} \\
\text { Study of Osteoporotic } \\
\text { Fractures }\end{array}$ & 2008 & USA & 5,386 & $100 \%$ & 76.7 & $\mathrm{mCHS}$ & Worsening IADL & $\mathrm{aOR}$ & 4.5 years & $5 / 8$ \\
\hline $\begin{array}{l}\text { Sarkisian et al. }{ }^{32} \\
\text { MacArthur Study of } \\
\text { Successful Aging }\end{array}$ & 2008 & USA & 1,118 & $55 \%$ & 74 & $\mathrm{mCHS}$ & incident $\geq 2 \mathrm{ADL}$ & $\mathrm{aOR}$ & 4years & $7 / 9$ \\
\hline
\end{tabular}




\begin{tabular}{|l|l|l|l|l|l|l|l|l|l|l|}
\hline Author/Study & Year & Location & $\begin{array}{l}\text { Sample } \\
\text { size* }\end{array}$ & $\begin{array}{l}\text { Female } \\
(\%)\end{array}$ & Age & $\begin{array}{l}\text { Frailty } \\
\text { criteria }\end{array}$ & $\begin{array}{l}\text { disability } \\
\text { outcome }\end{array}$ & $\begin{array}{l}\text { Effect } \\
\text { measure }\end{array}$ & $\begin{array}{l}\text { Follow- } \\
\text { up period }\end{array}$ & NOS \\
\hline $\begin{array}{l}\text { Bandeen-Roche et al.28 } \\
\text { Women's Health and } \\
\text { Aging Studies }\end{array}$ & 2006 & USA & $\begin{array}{l}612 \\
698\end{array}$ & $100 \%$ & $\geq 65$ & mCHS & $\begin{array}{l}\text { incident } \geq 3 \text { ADL } \\
\text { incident } \geq 3 \text { 3IADL }\end{array}$ & aHR & 3 years & $6 / 9$ \\
\hline $\begin{array}{l}\text { Boyd et al.29 } \\
\text { Women's Health and } \\
\text { Aging Studies }\end{array}$ & 2005 & USA & 749 & $100 \%$ & 78.0 & mCHS & Incident ADL & aHR & 3 years & $7 / 9$ \\
\hline $\begin{array}{l}\text { Woods et al.33 } \\
\text { Women's Health } \\
\begin{array}{l}\text { Initiative Observational } \\
\text { Study }\end{array}\end{array}$ & 2005 & USA & 39,911 & $100 \%$ & $\geq 65$ & mCHS & Incident ADL & aOR & 3 years & $6 / 9$ \\
\hline $\begin{array}{l}\text { Fried et al.2 } \\
\text { Cardiovascular Health } \\
\text { Study }\end{array}$ & 2001 & USA & 5,317 & $57.9 \%$ & $\geq 65$ & CHS & Worsening ADL & aHR & 3 years & 7 years \\
\hline
\end{tabular}

* Cohort used for analyses of interest or entire cohort if not available.

$\dagger$ Australia, Belgium, Denmark, France, Germany, Greece, Italy, the Netherlands, Spain, Sweden, and Switzerland.

+ Australia, Belgium, Canada, France, Germany, Italy, the Netherlands, Spain, the United Kingdom, and the Unites States

aHR: Adjusted hazard ratio

a/uOR: Adjusted/Unadjusted odds ratio

(I)ADL: (Instrumental) activities of daily living

mCHS: Modified Cardiovascular Health Study frailty index

mSOF: Modified Study of Osteoporotic Fractures frailty index

NOS: Newcastle-Ottawa scale 
Table 3. Types of measured ADL (A) and IADL (B)

A

\begin{tabular}{|c|c|c|c|c|c|c|c|c|c|c|}
\hline Author/Study & bath & dress & toilet & transfer & continence & feed & walk & groom & $\begin{array}{l}\text { cutting up } \\
\text { food }\end{array}$ & others \\
\hline Aguilar-Navarro et al. & $\mathrm{x}$ & - & - & $\mathrm{x}$ & $\mathrm{x}$ & $\mathrm{x}$ & $\mathrm{x}$ & - & - & \\
\hline Paulson et al. & $\mathrm{x}$ & $\mathrm{x}$ & - & $\mathrm{x}$ & - & $\mathrm{x}$ & $\mathrm{x}$ & - & - & \\
\hline Forti et al. & - & - & - & - & - & - & - & - & - & "activities of daily living" \\
\hline Abizanda et al. & $\mathrm{x}$ & $\mathrm{x}$ & $\mathrm{x}$ & - & - & $\mathrm{x}$ & - & $\mathrm{x}$ & - & \\
\hline Macklai et al. & $\mathrm{x}$ & $\mathrm{x}$ & $\mathrm{x}$ & $\mathrm{x}$ & - & $\mathrm{x}$ & - & - & $\mathrm{x}$ & \\
\hline Tom et al. & - & - & - & - & - & - & - & - & - & $\begin{array}{l}\text { "self-care, usual activities } \\
\text { (work, school, family)" }\end{array}$ \\
\hline Bilotta et al. & - & - & - & - & - & - & - & - & - & $\begin{array}{l}\text { "Basic Activities of Daily } \\
\text { Living (BADL)" }\end{array}$ \\
\hline Diaz de Leon Gonzalez et al. & - & - & - & - & - & - & - & - & - & "ADL" \\
\hline Lopes et al. & - & - & - & - & - & - & - & - & - & "modified Katz" \\
\hline Solfrizzi et al. & $\mathrm{x}$ & $\mathrm{x}$ & $\mathrm{x}$ & $\mathrm{x}$ & $\mathrm{x}$ & $\mathrm{x}$ & - & - & - & \\
\hline Al Snih et al. & $\mathrm{x}$ & $\mathrm{x}$ & $\mathrm{x}$ & $\mathrm{x}$ & - & $\mathrm{x}$ & $\mathrm{x}$ & $\mathrm{x}$ & - & \\
\hline Avila-Funes et al. & $\mathrm{x}$ & $\mathrm{x}$ & $\mathrm{x}$ & $\mathrm{x}$ & - & $\mathrm{x}$ & - & - & - & \\
\hline Sarkisian et al. & - & - & - & - & - & - & - & - & - & "Katz' 7 ADL" \\
\hline Bandeen-Roche et al. & $\mathrm{x}$ & $\mathrm{x}$ & $\mathrm{x}$ & $\mathrm{x}$ & - & $\mathrm{x}$ & - & - & - & \\
\hline Boyd et al. & $\mathrm{x}$ & $\mathrm{x}$ & $\mathrm{x}$ & $\mathrm{x}$ & - & $\mathrm{x}$ & - & - & - & \\
\hline Woods et al. & $\mathrm{x}$ & $\mathrm{x}$ & - & $\mathrm{x}$ & - & $\mathrm{x}$ & - & - & - & \\
\hline Fried et al. & - & - & - & - & - & - & - & - & - & "ADL" \\
\hline
\end{tabular}

B

\begin{tabular}{|c|c|c|c|c|c|c|c|c|c|c|c|}
\hline Author/Study & phone & shop & $\begin{array}{c}\text { food } \\
\text { preparation }\end{array}$ & housekeeping & laundry & transportation & medication & money & groom & map & others \\
\hline Aguilar-Navarro et al. & - & $\mathrm{x}$ & - & - & - & - & $\mathrm{x}$ & $\mathrm{x}$ & $\mathrm{x}$ & - & \\
\hline Abizanda et al. & $\mathrm{x}$ & $\mathrm{x}$ & $\mathrm{x}$ & $\mathrm{x}$ & $\mathrm{x}$ & $\mathrm{x}$ & $\mathrm{x}$ & $\mathrm{x}$ & - & - & \\
\hline Macklai et al. & $\mathrm{x}$ & $\mathrm{x}$ & $\mathrm{x}$ & $\mathrm{x}$ & - & - & $\mathrm{x}$ & $\mathrm{x}$ & - & $\mathrm{x}$ & \\
\hline Lopes et al. & & & & & & & & & & & "modified Lowton" \\
\hline Ensrud et al. & & & 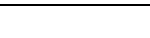 & & & & & & & & "5 IADLs" \\
\hline Avila-Funes et al. & $\mathrm{x}$ & $\mathrm{x}$ & - & $\mathrm{x}$ & $\mathrm{x}$ & $\mathrm{x}$ & $\mathrm{x}$ & $\mathrm{x}$ & $\mathrm{x}$ & - & \\
\hline Bandeen-Roche et al. & - & $\mathrm{x}$ & $\mathrm{x}$ & $\mathrm{x}$ & - & - & - & $\mathrm{x}$ & - & - & \\
\hline
\end{tabular}


Figure 1. Flow chart of systematic literature review

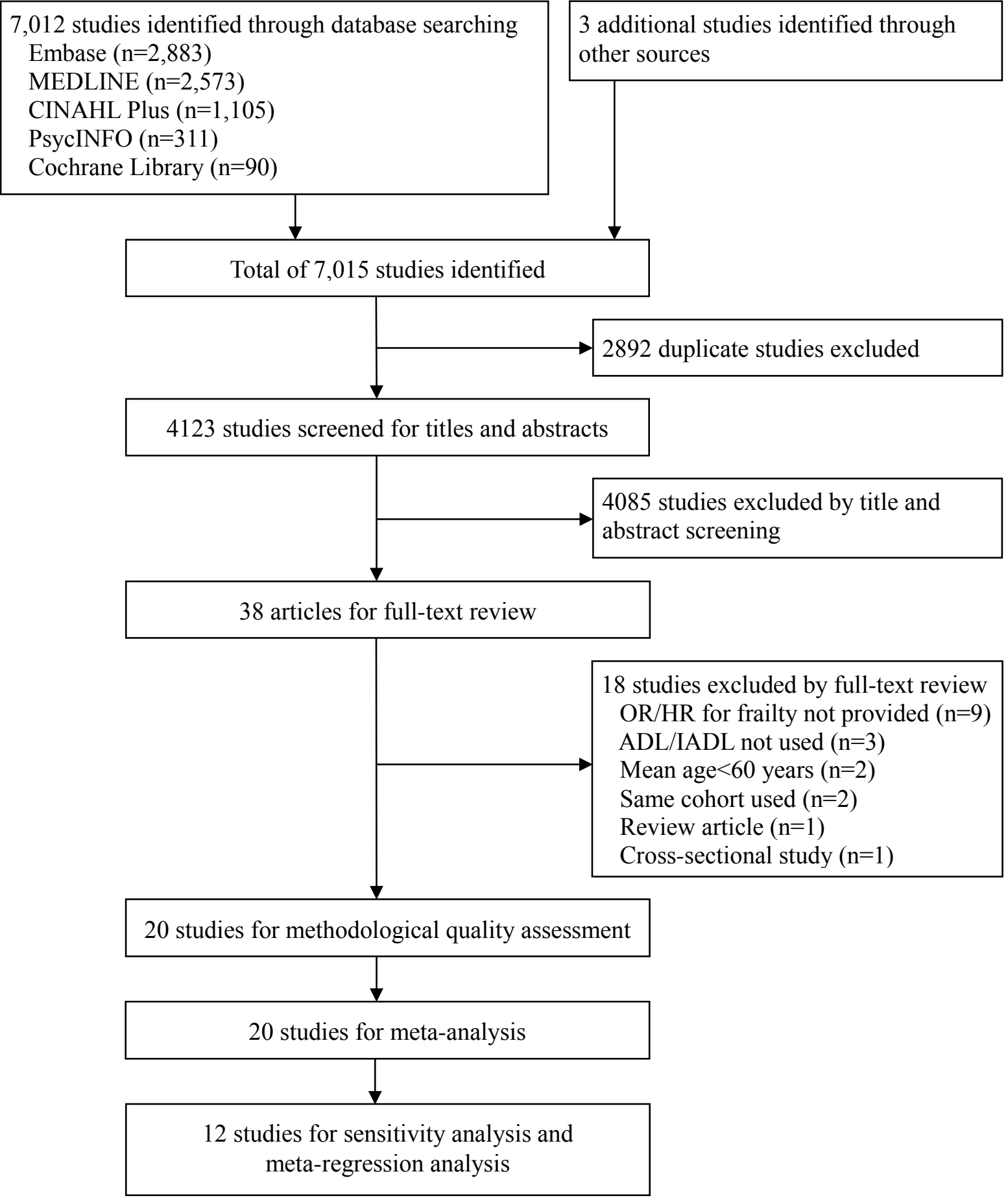


Figure 2A: Forest plots of incident, worsening, and combined ADL disability risks according to frailty and prefrailty compared with non-frailty among studies using odds ratios.

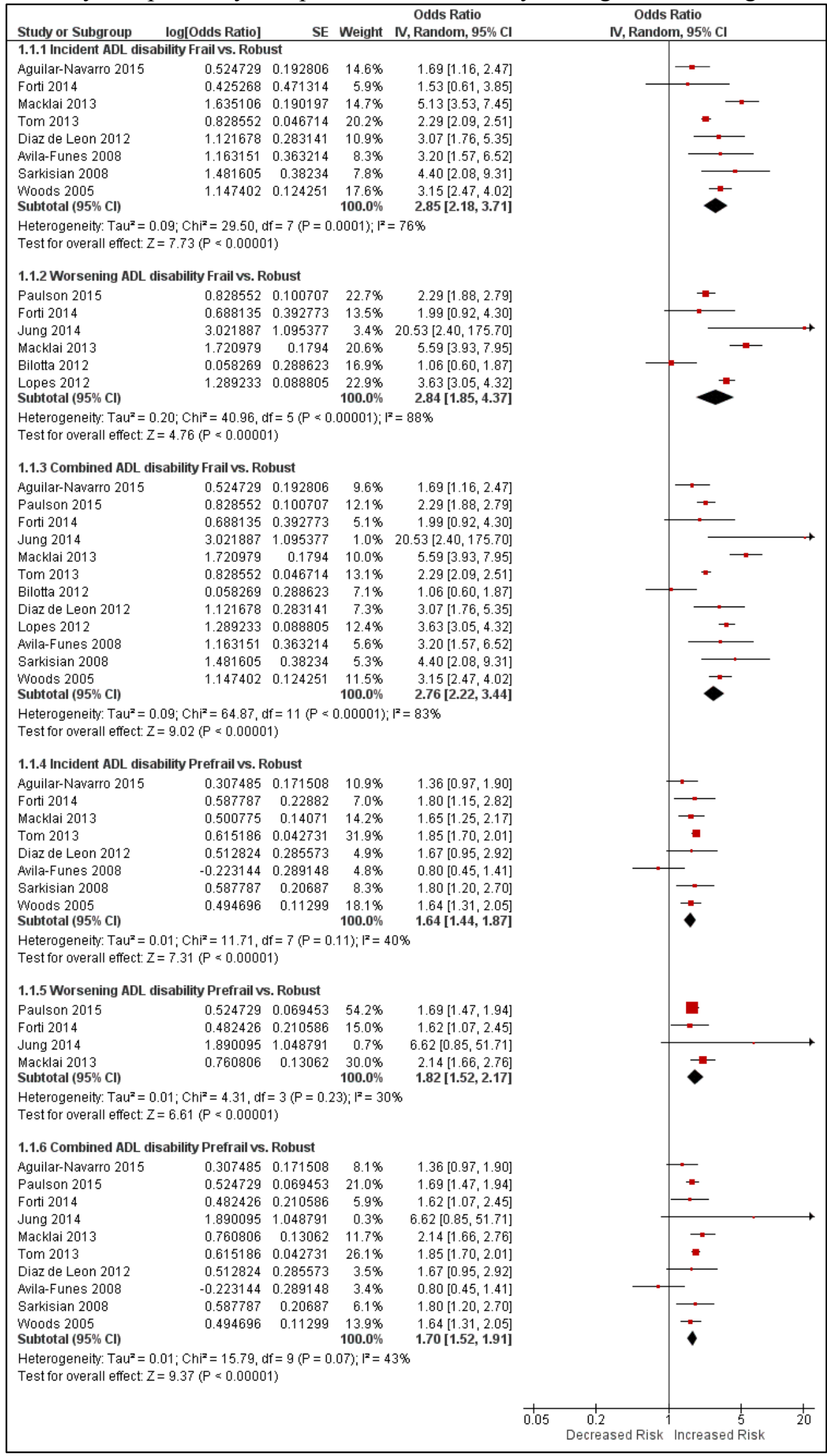


Figure 2B: Forest plots of incident, worsening, and combined ADL disability risks according to frailty and prefrailty compared with non-frailty among studies using hazard ratios.

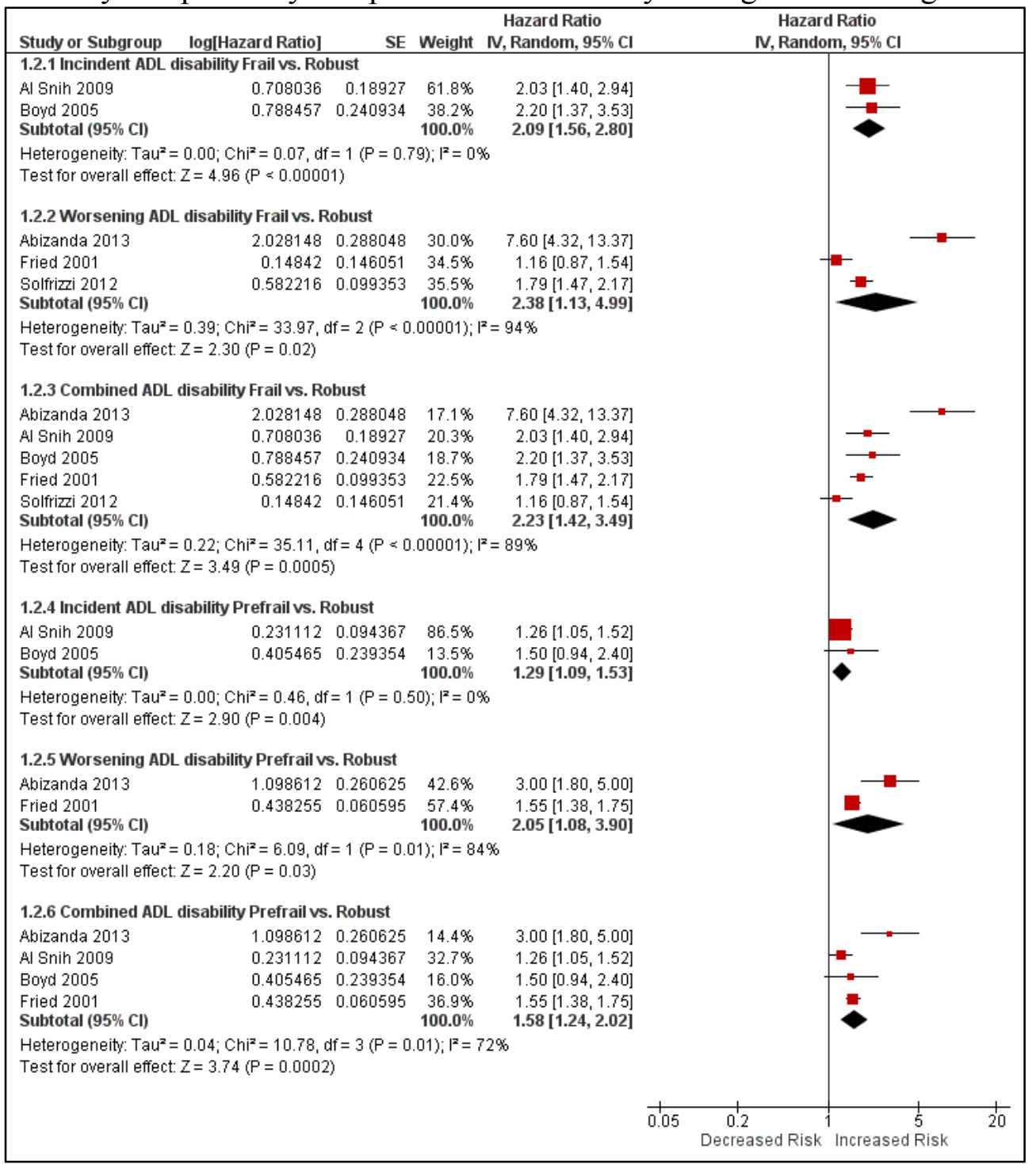


Figure 2C: Forest plots of incident, worsening, and combined IADL disability risks according to frailty and prefrailty compared with non-frailty among studies using odds ratios.

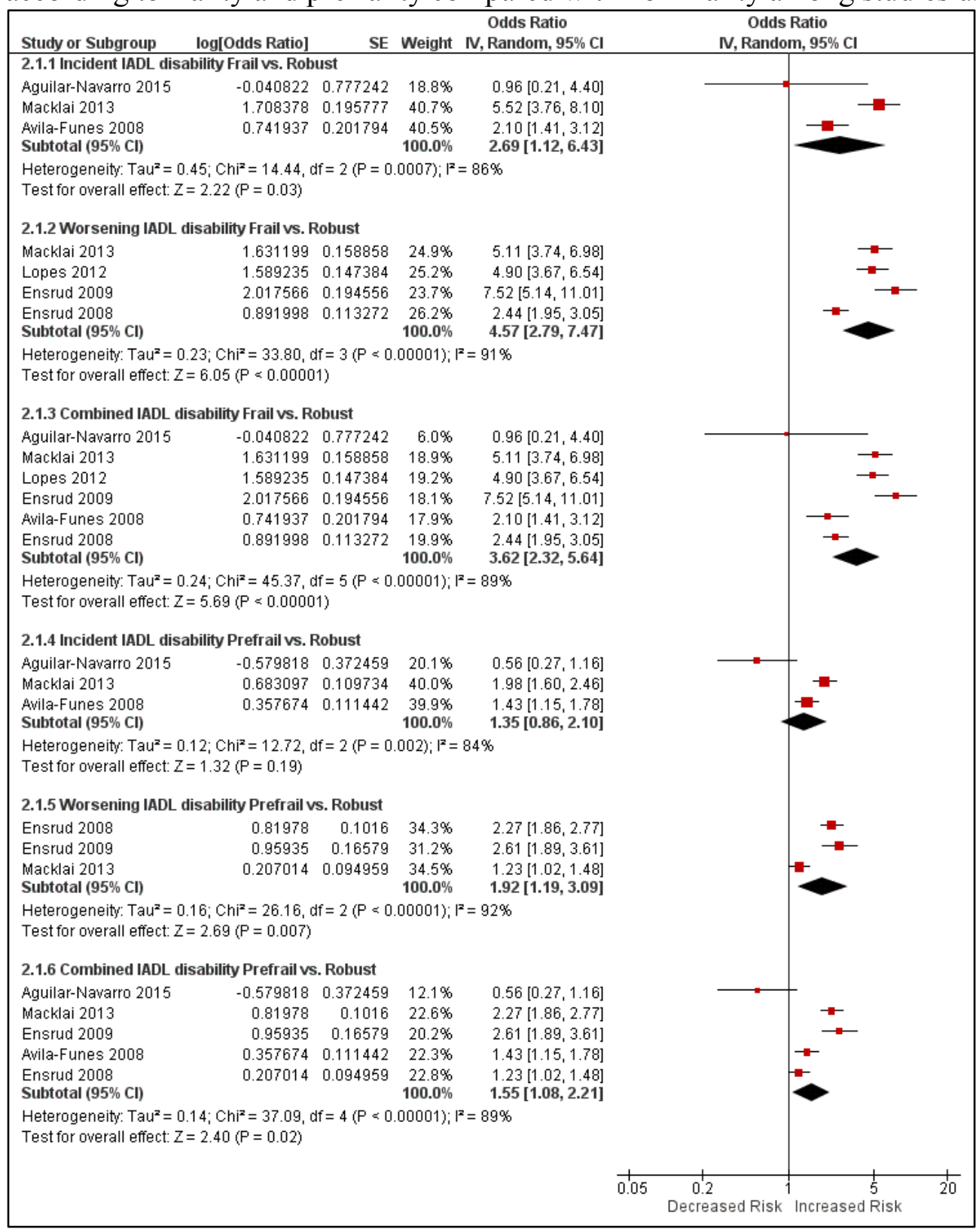


Figure 2D: Forest plots of combined IADL disability risks according to frailty and prefrailty compared with non-frailty among studies using hazard ratios.

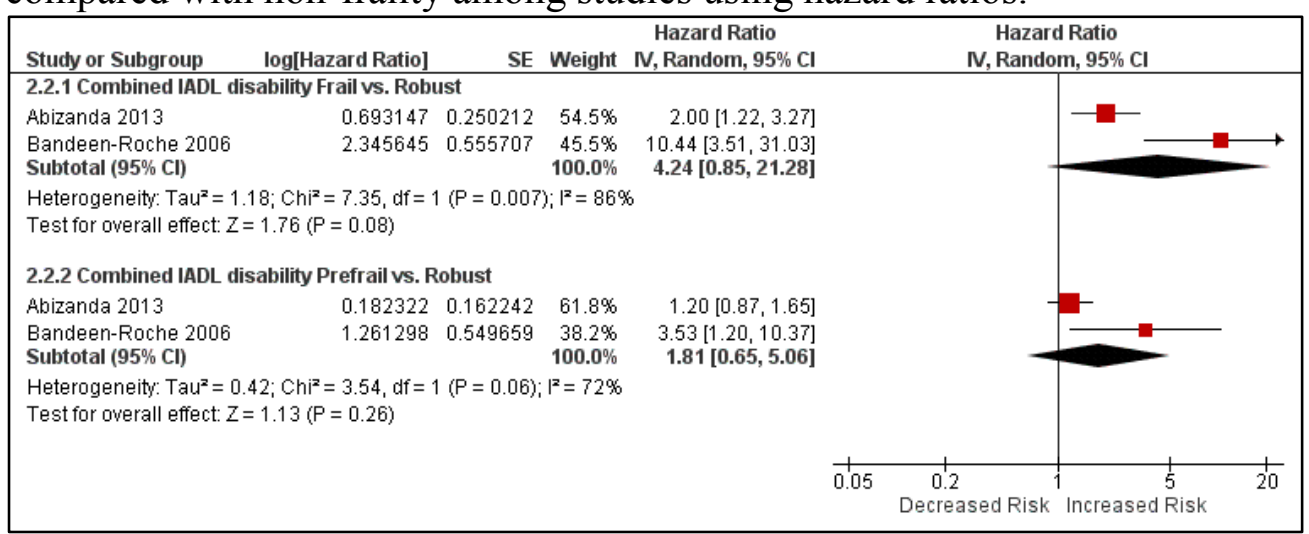

